\title{
How Does Suppliers' Fairness Affect the Relationship Quality of Agricultural Product Supply Chains?
}

\author{
Yuling Sun $\mathbb{D}^{1},{ }^{1}$ Zehua Liu $\mathbb{D}^{1},{ }^{1}$ and Hui Yang $\mathbb{D}^{2}$ \\ ${ }^{1}$ School of Economics and Management, Nanjing Tech University, Nanjing 211816, China \\ ${ }^{2}$ School of Economics and Management, Nanjing University of Science and Technology, Nanjing 210094, China \\ Correspondence should be addressed to Yuling Sun; syl_nj@163.com
}

Received 29 September 2017; Revised 7 January 2018; Accepted 22 January 2018; Published 19 February 2018

Academic Editor: Yong He

Copyright (c) 2018 Yuling Sun et al. This is an open access article distributed under the Creative Commons Attribution License, which permits unrestricted use, distribution, and reproduction in any medium, provided the original work is properly cited.

\begin{abstract}
Although many studies have suggested that the relationship between different supply chain members significantly affects agricultural product quality, suppliers' perceptions of fairness, which greatly influence their decisions on building the relationship quality, are often overlooked. Particularly, the empirical evidence to investigate the impacts of suppliers' fairness on the relationship quality and the factors that affect the suppliers' fairness is missing, and therefore this knowledge gap needs to be filled by new research. Herein, we conducted a survey of 450 agricultural product suppliers and systemically analyzed the impact of antecedents on fairness perception and the impact of fairness perception on relationship quality. In addition, we developed a structural equation model and found that information sharing and price satisfaction had significantly positive effects on procedural fairness and distributive fairness, respectively. Furthermore, our studies demonstrated that procedural fairness is more important in improving the relationship quality than distributive fairness. However, supplier dependence is another important impact factor, and it greatly decreases the positive effects of suppliers' fairness on relationship quality. In summary, the study results provide several managerial implications and extend our understanding of the importance of suppliers' fairness in the relationship quality, which involves product development with respect to the supplier's performance.
\end{abstract}

\section{Introduction}

Normally, retailers dominate in agricultural product supply chains. Although large retailers usually gain much more profits from a supply chain than suppliers, suppliers usually undertake most economic risks of the production and markets [1]. When suppliers realize that they are being treated unfairly, they might add unfavorable substances to accelerate the growth of agricultural products and increase the outputs for gaining more profits. The behaviors of suppliers to maximize their benefits have induced some food safety issues, such as melamine milk powders, glue steaks, and plastic seaweeds, which do not only harm the health of consumers, but also greatly damage the brand image of suppliers, leading to bankruptcy of suppliers and the disruption of the whole supply chain. Behavioral economics experiments have shown that people are not completely rational and have fairness perceptions. They do not only compare their own incomes to the incomes of others but also concern the fairness of the distribution and motivation.
Kumar et al. [2] pointed out that fairness is an important factor in determining the channel relationship quality and cooperation performance. People are always friendly to those who treat them fairly, while they punish those who treat them unfairly [3]. Samaha et al. [4] analyzed 500 manufacturing enterprises and their supply chain members through a linear hierarchy model, which proves that unfairness perceptions have a significantly negative impact on the relationship quality. Qin et al. [5] found that fairness perceptions enable enterprises to be more conducive to the performance of supply chains. Their research shows that fairness perceptions have a positive impact on the cooperation performance between the supplier and the retailer when both sides feel fairness during the cooperation. If either side does not feel fairness, the cooperation will not last long. Thus, a good supply chain operation requires fair relationships [6]. Only a fair market environment can enhance the cooperation between the supplier and the retailer and motivate the supplier to improve the product quality. However, current research on fairness perceptions 
mainly focuses on psychology, sociology, and other fields and ignores the roles of supplier fairness perceptions in Chinese agricultural supply chains. Therefore, we performed studies to investigate the antecedents of perceived fairness and its impacts on the quality of supply chain relationships.

Our studies focus on the relationship quality in agricultural product supply chains and suppliers' fairness. We assume that suppliers' fairness may affect the relationship quality of agricultural product supply chains, and suppliers will not trust retailers. As a result, the agricultural product supply chain cannot achieve the maximal profits, and retailers may decrease the ordering quantity and even switch to other suppliers. Although current studies often highlight the importance of the retailer's fairness perception in regard to repurchase intentions, we found that the supplier's fairness perception could also significantly impact the relationship quality in agricultural product supply chains.

Previous studies focused on fairness from many different dimensions but overlooked the factors related to the relationship between suppliers' fairness and the relationship quality. For instance, Samaha et al. [4] did not distinguish between three dimensions of fairness; Luo [7] focused solely on procedural justice; and Kumar et al. [2], Yilmaz et al. [8], Brown et al. [9], and Griffith et al. [10] focused on procedural and distributive justice. In contrast, we examined the relationship between supplier fairness and relationship quality. In addition, supplier dependence is another important factor that could affect the trust between suppliers and retailers, and therefore we examine its impact on the trust between the suppliers and the retailers, for the first time.

In light of these research gaps, the central issues addressed in this research focus on investigating the impact of two dimensions of supplier fairness on relationship quality. We use survey data from 450 agricultural product suppliers to explore the effect of antecedents (including information sharing, price satisfaction, and environmental stability) on fairness perceptions and the effect of fairness perceptions on relationship quality. In addition, we investigated moderating effects of suppliers' dependence on fairness perceptions, which consequently affect relationship quality (i.e., trust and commitment). Furthermore, the indirect effect of antecedents on relationship quality of agricultural product supply chains was also studied.

The contributions of our studies are fourfold. First, supplier fairness perceptions were utilized as an independent variable to analyze the impacts of this perception on trust among members of the agricultural product supply chains. Second, we studied the relationship between procedural fairness and the agricultural product supply chains. We found that the two latitudes can reflect fairness perceptions more comprehensively than the fairness of latitude alone. Third, our studies characterized the direct and indirect effects of fairness with survey data, which is important because the antecedents of fairness are not directly portrayed in extant researches. Therefore, a consideration of the output of relational quality is required to understand this phenomenon [11]. In addition, we also considered retailer dependence as a key factor in the supply chain management of agricultural products for the first time and included it in this study.
Fourth, unlike previous studies, ours investigated the impact of retailer dependence on trust. Our research will greatly promote the studies of the theories of fairness and food supply chain management because many suppliers depend on their retailers for survival.

The remainder of our study is organized as follows. Section 2 provides a theoretical background analysis and presents the hypotheses as well as a supplier-retailer relationship performance model. Section 3 introduces our detailed questionnaire design and tests the validity and reliability of our studies. Section 4 reports our survey results and verifies the appropriateness of its assumptions. Section 5 provides discussion and management implications with our survey data and provides conclusions and points out possible directions for the future research.

\section{Theoretical Background and Hypotheses}

2.1. Fairness Theory. The fairness or justice theory is derived from exchange and equilibrium theories in the field of sociology and economics. Adams [12] argued that interperson fairness perceptions were primarily derived from comparing one's ratio of outcomes and inputs with others'. Further studies suggested that fairness perceptions are a critical factor in maintaining a cooperative relationship at interorganizational enterprise levels $[2,13]$. In fairness theory, fairness is often divided into four dimensions: distributive fairness, procedural fairness, interpersonal fairness, and informational fairness. Distributive and procedural fairness are based on structural aspects [14]. Interpersonal fairness and informational fairness are based on people's reactions and social interactions $[15,16]$. Interpersonal fairness focuses on the degree to which people are treated with dignity, politeness, and concern by employers in inner enterprise [16]. It usually plays an important role in an organization that has specific superior and subordinate relationships. In contrast, informational fairness refers to conveying information, including why procedures are formulated in a certain way and why profits are distributed in a certain fashion [17]. The informational fairness is always prominent in a relatively equal relationship.

Distributive fairness was introduced by Adams [12], who confirmed that people's outcome comparison with others' is the main element considered by people when they judge if they were treated fairly. On the personnel level, the formation of distributive fairness is associated with the difference of individual profits. Extended to circumstances involving supply chains and strategic enterprise alliances, distributive fairness is formed in situations in which both parties in the partnership distribute their common earnings in view of each party's contributions, commitment, and responsibility [18]. Because there is a closed relationship between distributive fairness and incomes, distributive fairness can have a strong impact on profit satisfaction. Especially in agricultural product supply chains, most suppliers are in a disadvantaged position, due to the uncertainty of supply demands. The profit of suppliers is so small that they become more sensitive if they are treated unfairly; and, hence, distributive fairness is important for agricultural product suppliers. 
In addition, procedural fairness was proposed by Thibaut and Walker [19], and they suggested that people often focus on the fairness of transaction processes, which are used to determine the distribution outcomes of resources and incomes. There are some common grounds between procedural fairness and distributive fairness. For instance, high incomes increase the levels of both procedural and distributive fairness. However, different from distributive fairness, people will perceive the presence of greater procedural fairness when they believe they can control the procedures in question or when they realize that the policies and practices could protect their interests. Procedural fairness was proved to be more important in supply chain circumstances [2022]. The existence of procedural fairness not only significantly increases the enterprise's integrated performance but also affects cooperative satisfaction.

There are a number of studies about fairness perceptions, which suggest that fairness perception has a positive effect on relationship quality. However, most studies only focused on retailers but neglected the fairness perception of suppliers, especially in the agricultural product industry. Thus, in line with Zaefarian et al. [23], our studies will focus on fairness perceptions in regard to agricultural suppliers, rather than other industries or retailers.

Distributive and procedural fairness gained popularity in studying the supply chain relationship $[2,8,9,13]$. However, in an agricultural product supply chain, the relationship between suppliers and retailers is typically a loose interorganization cooperation. Moreover, retailers are usually in a dominant position in agricultural product supply chains, and suppliers focus on profits and the procedure of distribution. Therefore, the distributive fairness and procedural fairness are more important than interpersonal fairness and informational fairness in agricultural product supply chains. Our work focuses on the distributive fairness and procedural fairness.

2.2. Relationship Quality. Relationship quality is defined as consisting of characteristics that can reveal the quality of relational ties between two sides in a transaction [24]. In sale channels, better relationship quality can not only decrease the uncertainty of consumers, but also gain consumers' trust $[25,26]$. In addition, the relationship between business partners also involves the standards that are used to assess and cognize the commercial intercourse results in business cooperation [27]. Relationship quality consists of multifarious dimensions. In view of interactive relationships and relational benefits, the dimensions of relationship quality, including commitment, cooperation, trust, communication, participation, and skills, are needed to solve conflicts together $[28,29]$. In social psychological and strategy alliances, the dimensions of relationship quality refer to tie strength, endurance, frequency, diversity, flexibility, and fairness [30]. There are also some studies that consider trust and commitment as basic construct dimensions of business relationship quality [31,32]. Moreover, trust and commitment completely capture the essential aspects of supplier-retailer relationships. They are also preconditions to many other dimensions, such as satisfaction and cooperative relationship values. In light of the importance of these two dimensions, we consider trust and commitment as two prime dimensions in this study to define relationship quality.

In behavior theory, trust is defined as an irrational behavior and could be imperative to cooperative relationships in supply chains [33]. Extending to the interorganization scenario, trust means that enterprises care about their partners altruistically and share their common earnings bountifully [34]. Ruyter et al. [35] argued that trust is a driving power arising from spontaneous reliance on partners. Because of the different definitions of trust, trust is multifaceted. Zucker [36] divided trust into two dimensions, which are based on personal and institutional elements, respectively. In psychology, studies related to trust mostly focus on interpersonal trust. In supply chain relationships, enterprises pay more attention to interorganizational trust, which consists of more reliability and benevolence than interpersonal trust [37]. In this study, we agree with Anderson and Narus's [33] studies in regard to capturing the characteristics of trust for agricultural suppliers. We posit that trust encompasses honesty and benevolence. In comparison with trust, honesty is the belief that partners keep their word and fulfill obligations sincerely. Benevolence means that suppliers are firmly convinced that the retailer is concerned about the suppliers' welfare and will not take unexpected actions that would have a negative impact on suppliers. According to supply chain members' cognition in regard to ability and integrity, trust exerts an impact on relationship value and changes supply chain members' behavior. If the trust level between firms and their partners is high, it becomes impossible to adopt opportunistic behaviors. Meanwhile, with the support of trustworthy partners, the market and technical risks of firms will be minimized.

Commitment is also a basic dimension of relationship quality; and its importance is acknowledged by many researchers (e.g., [32, 38]). To some extent, commitment is a ramification of trust; and some researchers believed that commitment refers to the confidence of partners' trust and honesty $[39,40]$. In interorganizational relationships, commitment embodies the willingness to maintain a longlasting partnership launched by a contract [41]. Higher levels of commitment will cause enterprises to make more economical profits [42]. In cooperative relationships, the existence of commitment means that partners will take on the costs of commitment, searching, and finality into consideration, and their partners will not readily turn to alternatives. Commitment promotes the sharing of information and technology among enterprises; hence, there will be a greater appreciation of information and technology. Figure 1 depicts the theoretical model of supplier-retailer relationship performance which is elaborated upon in detail as shown below.

2.3. Antecedents of Fairness Perception. Various supply chain studies indicate that people's fairness perception will be influenced by a number of different factors. For example, Kumar et al. [2] argued that distributive fairness is connected to outcomes. In regard to supply chain relationships, studies of suppliers and manufacturers argue that the benefits of distribution and risk sharing are principal factors that 


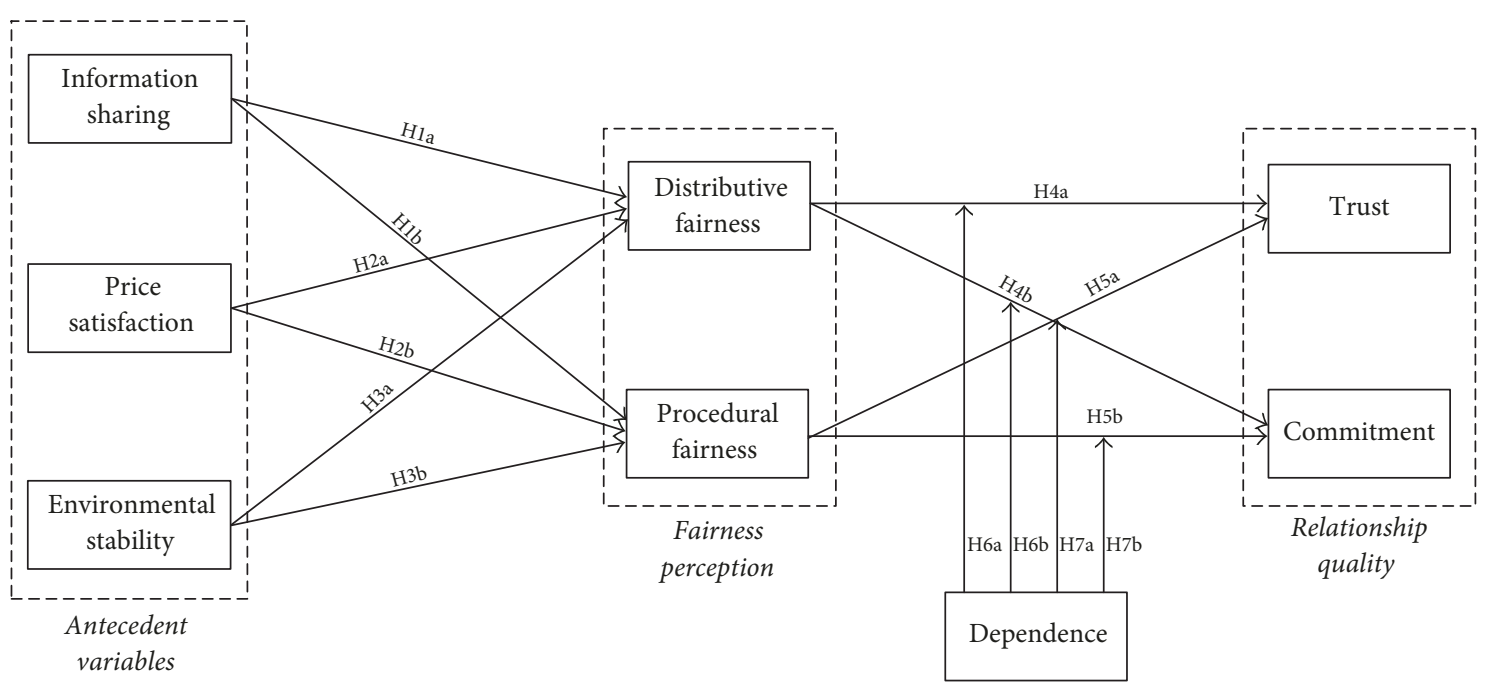

FIgURE 1: A theory model of supplier-retailer relationship performance.

affect distributive fairness. However, existing studies do not conduct further research on the antecedents of fairness perceptions. In our study, we will explore how information sharing, price satisfaction, and environmental stability affect people's fairness perceptions.

Organizational studies suggest that enterprises information can be broken down into strategy information, transaction information, and operational information [43]. Information sharing improves the management efficiency and operational performance of a supply chain [44]. In supply chain relationships, there are lower levels of information risks and higher levels of overall supply chain performance if enterprises share information [45, 46]. Thus, sharing information is the key factor to allocate resources efficiently, save on transaction costs, and improve the use ratio of information resources. It has been shown that knowing a partner's profit information can make enterprises feel like being treated fairly [5]. Meanwhile, sharing information with a partner about one's own initiative is regarded as a signal of kindness and fairness. However, if an enterprise shares too much confidential information with a partner, this will put the enterprise in a disadvantaged position and hurt the perception of fairness. This characteristic is more obvious in agricultural supply chains. Agricultural product retailers possess a great deal of information about clients, competitors, and enterprise operations, which allows retailers to dominate transaction details such as procurement regulations and prices [47]. Therefore, only rational information sharing can guide agricultural suppliers to make accurate decisions about the output of agricultural products and then reduce unsalable products and meet market requirements. Hence, we believe that effectively using acquired information and rationally sharing information with partners can greatly promote fairness perception, cooperation performance, and supply chain stability. Consequently, we hypothesize the following:

$H 1 a, b$ : information sharing has a significant positive effect on distributive fairness (a) and procedural fairness (b).
Price is considered to be one of the most important factors that will increase a supplier's fairness perceptions. As far as suppliers are concerned, the impact of price on a longlasting supply chain is complicated, due to the complexity of the relationship ages, the cooperative nature of relationships, and various market circumstances. Hellberg-Bahr and Spiller [48] suggested that suppliers compare the procurement prices proposed by different retailers before they sell products. This behavior is becoming an important factor in forming price satisfaction and fairness. However, in agricultural supply chains, suppliers lack pricing power because of their inferior position. Therefore, suppliers will pay more attention to retailers' procurement pricing criteria, which involve examining product quality, purchase quantity, geographic position, and relationship age [49]. We argue that the impact of price satisfaction on fairness perception is not only related to whether agricultural suppliers can fairly gain profits or not but also connected to the endurance and stability of the cooperative relationship in question. Therefore, suppliers are sensitive to prices and high levels of price satisfaction will effectively enhance the cooperative stability of the supply chain in question. Thus, we propose the following:

$H 2 a, b$ : price satisfaction has a positive impact on distributive fairness (a) and procedural fairness (b).

Environmental stability is defined as the ability of an enterprise to forecast the future markets, policies, and other factors accurately, according to the current external environment [50]. The external environment is the prime factor that is considered before enterprises make decisions. When market circumstances are unstable, enterprises usually do not want to be risk averse. They will reduce their dependence on a single partner to maintain their level of flexibility [51]. Kumar et al. [2] demonstrated that an uncertain environment will weaken the positive impact of fairness perception on relationship quality. Many unpredictable factors will emerge in a stagnant market environment. In psychology, growing uncertainty makes enterprises become more suspicious of 
each other, which is not conducive to constructing favorable cooperative relationships. This phenomenon is more general in the agricultural product market because suppliers are always facing uncertain external environments, such as price fluctuations and changes of climate. Thus, these suppliers are more inclined to be affected by the external environment. Nevertheless, a stable environment can enable suppliers to prepare for future variations in advance. Consequently, they could optimize their relationships with retailers. Thus, we suggest the following:

$H 3 a, b$ : environmental stability is positively related to distributive fairness (a) and procedural fairness (b).

\subsection{Fairness Perception and Relationship Quality. A number} of studies have examined the influence of fairness perceptions on relationship quality. Aryee et al. [52] argued that distributive fairness and procedural fairness had remarkable positive effects on relationship quality. Luo [18] proved that procedural fairness and interpersonal fairness were conducive to relationship quality. Ellis et al. [53] showed that procedural fairness was more important than informational fairness. Liu et al. [14] proved that procedural fairness and informational fairness were important in relationship quality, and therefore procedural fairness is more significant.

In the literature on supply chain management, evidence exists to support the argument that fairness perceptions are closely linked to honesty and benevolence in regard to trust [54]. Based on research conducted in the automotive industry, Zaefarian et al. [23] suggested that fairness perceptions led to high levels of trust. Hemmert et al. [55] pointed out that suppliers' trust in the buyer can be promoted by establishing fairness in the supplier-buyer relationship. In agricultural supply chains, the effect of distributive fairness perception and procedural fairness perception on trust may be particularly prominent because the positions of suppliers and retailers are asymmetrical. Highly favorable distributive fairness promotes mutual trust between suppliers and retailers, leading to a willingness to maintain long-term cooperation $[10,52]$. In fact, favorable mutual trust eliminates opportunistic behavior caused by ineffective communication and conflicts of interest in interorganizational relationships. Accordingly, this causes the willingness of involved parties to maintain cooperation and plays an important role in improving market vitality. Thus, we propose the following:

$H 4 a, b$ : both distributive fairness (a) and procedural fairness (b) have positive effects on trust.

Commitment in this context is defined as an ongoing relationship with another and is important enough to warrant a great deal of effort to maintain it [50]. According to Kumar et al. [2], procedural fairness has a relatively strong influence on commitment, compared with distributive fairness. Furthermore, with the deepening of cooperation, suppliers pay more attention to procedural fairness, instead of distributive fairness, and they also expect to acquire respect, not just lucrative returns, from retailers. Suppliers cannot perceive favorable commitment when they lack respect, even if retailers have already successfully maintained high levels of distributive fairness with suppliers [56]. In agricultural product supply chains, the characteristics of commitment are embodied by the contracts. Nonperformance behaviors, such as rejection or postponing deliveries, may pose risks to suppliers. Moreover, agricultural products are usually perishable, and these behaviors may not only result in huge losses to suppliers, but also disturb the stability of the product supplies and prices. Thus, we posit the following:

$H 5 a, b$ : distributive fairness (a) and procedural fairness (b) have positive effects on commitment.

2.5. The Moderating Effect of Dependence. In supply chain channels, dependence refers to an enterprise's need to maintain a relationship with a partner, in order to fulfill the enterprise's objectives [57]. If the ability of an enterprise to replace a partner is deficient, we posit that the enterprise is dependent upon its partners [58]. Dependence consists of two concepts: total interdependence (the sum of both enterprises' dependence) and asymmetrical interdependence (the difference in the enterprises' dependence) $[59,60]$. Dependence can have a strong impact on maintaining a dyadic relationship [61]. In a supply chain, support and coordination between members can ensure effective operation. Upstream suppliers, such as manufacturers, need an adequate supply of raw materials and timely delivery services. Downstream retailers need a stable supply of products and stable market demand. However, when asymmetrical interdependence exists on a large scale, the more powerful supplier is likely to perform opportunistic behaviors to maximize their own profits due to low risks. We propose that, in agricultural supply chains, suppliers depend heavily on retailers. In terms of the numbers, relatively few retailers and a number of suppliers consistently lead to the supply of agricultural products beyond the requirements at hand. Moreover, agricultural suppliers expect to sell products as soon as possible because of the perishable nature of the products. Consequently, intensive sale willingness increases the dependence of suppliers on retailers. Thus, we propose that there exists highly asymmetrical interdependence between suppliers and retailers.

As symmetrical interdependence increases, the occurrence of divergence and conflict decreases. So, symmetrical dependence therefore has a positive effect on relationship quality. Excessive asymmetrical interdependence, on the other hand, increases powerful enterprises' ability to replace partners and, therefore, could damage the trust and commitment between supply chain numbers. Relationship quality decreases a lot due to unfair treatment in an asymmetrical relationship and a lack of incentives to cultivate trust and commitment with partners. Therefore, we believe that the more the suppliers depend on retailers; the less the influence of suppliers' fairness perceptions on relationship quality will be. Furthermore, dependence more likely leads to building cooperative circumstances and affects relationship quality indirectly. Thus, we hypothesize the following:

$H 6 a, b$ : the positive effect of distributive fairness on trust (a) and commitment (b) is smaller once considering suppliers' dependence on retailers. 
$H 7 a, b$ : the positive effect of procedural fairness on trust (a) and commitment (b) is smaller once considering suppliers' dependence on retailers.

\section{Methodology}

3.1. Sample and Data Collection. We tested our hypotheses using matched supplier data drawn from the agricultural product industry in Jiangsu province, which is located in East China. Jiangsu is a developed province, especially in regard to agriculture. There are a large number of agricultural product suppliers in Jiangsu. There are also wholesale distributors of agricultural products, as well as foreign supermarkets, such as Carrefour, Walmart, and PARKnSHOP. This presents ideal circumstances in which we can empirically examine supplier-retailer relationships. Generally, suppliers in Jiangsu province are single working class households with relatively limited number of partners. The suppliers usually cooperate with a few fixed retailers. On the other hand, there are multiple households that supply agricultural products to retailers at the same time. Consequently, the differences between suppliers and retailers lead to tense supplier-retailer relationships, which have aroused extensive concerns for the Chinese government. Suppliers are unable to earn satisfactory profit due to being in a weak position in the supply chain. This situation can not only decrease suppliers' fairness but also decrease the quality of agricultural products. Therefore, it is necessary to study fairness issues in this context to alleviate the tense relationships in this situation.

We designed a series of questionnaires for suppliers. The original questionnaires were designed first in English, and then the English version was translated into Chinese and back-translated into English to ensure the accuracy of the translation. The differences between the original and back-translated English versions were checked by professional translators, and we refined some questions. In the data collection process, we conducted face-to-face interviews as well as mailing questionnaires to 1,000 informants in Jiangsu province. The common characteristics among these informants were shown as follows: all of them are working class households and have cooperative relationships with supermarkets or other agricultural product retailers. All questionnaires were anonymous, and we guaranteed confidentiality of data to avoid evaluation apprehension in respondents.

After a month, we received 562 questionnaires. To verify each informant's knowledge of suppliers' cooperative relationships with retailers, as well as their levels of knowledgeability in regard to the survey, we used a seven-point Likert scale ( 1 = "very low" and 7 = "very high"). We removed 112 informants with scores less than 4 for these questions and ended up with a final supplier sample consisting of 450 participants. The response rate is around 45\%, which is adequate for empirical studies. The average operation duration of our supplier samples was approximately five years. A total of $38.9 \%$ of suppliers reported annual revenues of less than $¥ 0.5$ million, $32.4 \%$ reported annual revenues of $¥ 0.5$ - $¥ 1$ million, $19.8 \%$ reported annual revenues of $¥ 1-$ $¥ 2$ million, and $8.9 \%$ reported annual revenues greater than
$¥ 2$ million. After the data collection, we conducted a revisit survey with a sample of 50 nonresponding informants, to assess nonresponse bias. We compared these 50 informants with respondents' data and found that there were no significant differences between responding informants and nonresponding informants. Thus, nonresponse bias did not have an influence on our data.

3.2. Variables and Measurements. We used multi-item models to measure the validity and reliability of our supply chain relationship study. Table 1 outlines the final set of construct scales, Cronbach's alphas, and item loadings. All the items in our construct scales were derived from existing studies, and we made reasonable adjustments to meet our research targets. Antecedents of fairness perception were defined as consisting of three dimensions: information sharing, price satisfaction, and environmental stability. The items for these three dimensions were adapted from Frazier et al. [62], Hellberg-Bahr and Spiller [48], and Heide and John [58] and consisted of six, five, and four items, respectively. Fairness perceptions in our study were conceptualized as two dimensions: distributive fairness and procedural fairness. Distributive fairness is rooted in Price and Mueller [63], with five items, and procedural fairness is rooted in Kim and Mauborgne [64] and Konovsky and Cropanzano [65], with eight items. The construct of relationship quality had several different operational alternatives. In prior literature, relationship quality was usually composed of trust and commitment. Therefore, the measure for trust was adapted from the items posited by Kumar et al. [2], which consist of honesty and benevolence, with five items each. Commitment was adapted from Meyer et al. [66], with three items. Dependence referred to the dependence of suppliers on retailers; it was derived from Frazier et al. [62] and measured through four items.

Due to the constructs of variables being derived from existing literature, we conducted several steps to ensure that the constructs are applicable to our study and to assess the robustness and validity of the constructs. First, we performed an exploratory factor analysis (EFA) on our data. The reliability of the variables was validated by favorable Cronbach's alphas and all of the indexes were greater than 0.72 , shown in Table 1 . Second, we conducted a confirmatory factor analysis (CFA) using the maximum likelihood method in AMOS 22.0 to evaluate the measurement validity of the constructs [67]. Our CFA results showed a goodness of fit with the data: $\mathrm{df}=947, \chi^{2} / \mathrm{df}=1.39$, RMSEA $=0.03$, GFI $=$ $0.90, \mathrm{CFI}=0.96$, TLI $=0.95$, and IFI $=0.96$. In accordance with the standard of goodness of fit $[68,69], \chi^{2} / \mathrm{df}<0.2$, RMSEA $<0.05$, GFI, CFI, TLI, and IFI were all equal to or greater than 0.90 , thereby confirming a favorable goodness of fit. For convergent validity, all item loadings were greater than 0.64 and significant $(p<0.01)$, and the composite reliability of all the variables ranged from 0.72 to 0.83 , showing satisfactory convergent validity (see Tables 1 and 2). We also verified discriminant validity by evaluating average variance extracted (AVE) from each construct; we confirmed that it was greater than the squared correlations between all the construct pairs [70], further demonstrating discriminant validity. 


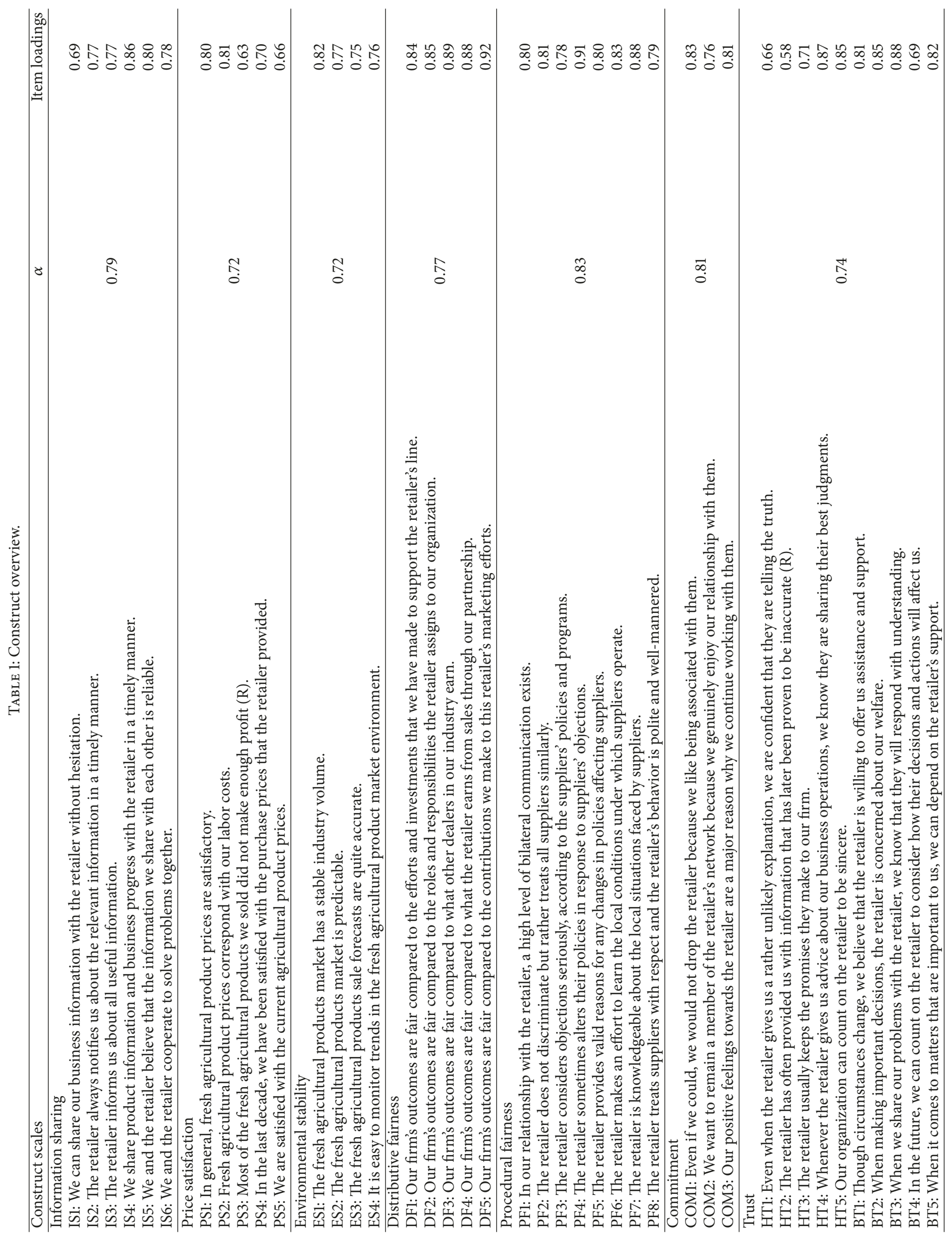




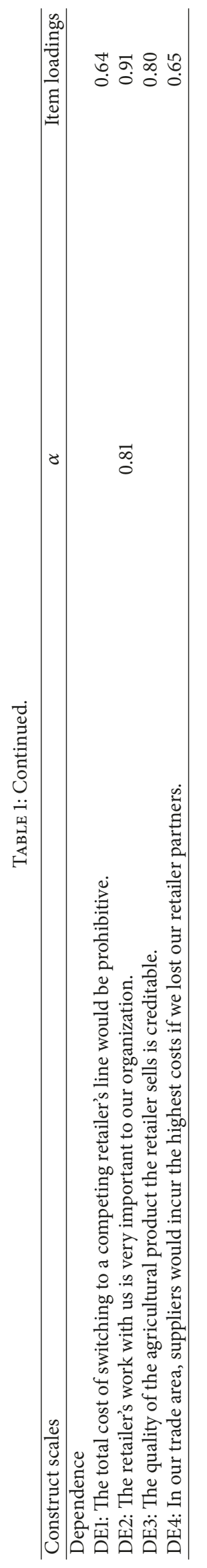


TABLE 2: Means, standard deviations, AVE, CR, correlation matrix, and goodness of fit.

\begin{tabular}{|c|c|c|c|c|c|c|c|c|c|c|c|c|}
\hline & \multirow{2}{*}{$\mathrm{M}$} & \multirow{2}{*}{ SD } & \multirow{2}{*}{ AVE } & \multirow{2}{*}{ CR } & \multicolumn{8}{|c|}{ Correlation matrix } \\
\hline & & & & & (1) & (2) & (3) & $(4)$ & $(5)$ & (6) & (7) & (8) \\
\hline (1) Information sharing & 4.62 & 1.12 & 0.61 & 0.90 & 1.00 & & & & & & & \\
\hline (2) Price satisfaction & 4.76 & 1.12 & 0.52 & 0.74 & $0.73^{* * *}$ & 1.00 & & & & & & \\
\hline (3) Environmental stability & 4.67 & 1.15 & 0.60 & 0.71 & $0.60^{* * *}$ & $0.53^{* * *}$ & 1.00 & & & & & \\
\hline (4) Distributive fairness & 4.78 & 1.02 & 0.77 & 0.94 & $0.69^{* * *}$ & $0.79^{* * *}$ & $0.61^{* * *}$ & 1.00 & & & & \\
\hline (5) Procedural fairness & 4.74 & 1.06 & 0.68 & 0.94 & $0.87^{* * *}$ & $0.74^{* * *}$ & $0.74^{* * *}$ & $0.71^{* * *}$ & 1.00 & & & \\
\hline (6) Trust & 4.62 & 1.17 & 0.64 & 0.94 & $0.80^{* * *}$ & $0.72^{* * *}$ & $0.75^{* * *}$ & $0.71^{* * *}$ & $0.78^{* * *}$ & 1.00 & & \\
\hline (7) Commitment & 4.92 & 1.11 & 0.61 & 0.73 & $0.73^{* * *}$ & $0.71^{* * *}$ & $0.74^{* * *}$ & $0.76^{* * *}$ & $0.82^{* * *}$ & $0.76^{* * *}$ & 1.00 & \\
\hline (8) Dependence & 4.71 & 1.11 & 0.59 & 0.93 & $0.35^{* * *}$ & $0.37^{* * *}$ & $0.50^{* * *}$ & $0.37^{* * *}$ & $0.41^{* * *}$ & $0.46^{* * *}$ & $0.50^{* * *}$ & 1.00 \\
\hline & & & & & Good & ess of fit & & & & & & \\
\hline$\chi^{2} / \mathrm{df}$ & & $\mathrm{f}$ & & & & GFI & & & & & & IFI \\
\hline 1.39 & & & & & & 0.90 & & & & & & 0.96 \\
\hline
\end{tabular}

\section{Results}

After demonstrating the validity and reliability of the data, we introduced three constructs of the antecedents (information sharing, price satisfaction, and environmental stability), two constructs of fairness perception (distributive fairness and procedural fairness), and two constructs of relationship quality (trust and commitment) and dependence (see Figure 1). Because fairness perceptions, trust, and commitment are behavior indexes, they usually contain some measurement variations. Structural equation modeling (SEM), a popular statistical methodology for experimental research [14], allows independent variables and dependent variables to contain measurement variations and deal with multiple dependent variables at the same time. SEM can also deal with the complex affiliation of an index that belongs to multiple factors, and therefore it is a method that is precisely necessary for studying the supplier-retailer relationship in agricultural product supply chains. We conducted SEM with maximum likelihood estimation in AMOS 22.0 to test our hypotheses, which enabled us to test influences with multiple structural paths.

To examine the hypotheses, we proposed ( $\mathrm{H} 1, \mathrm{H} 2$, and H3) and analyzed the path from antecedents to fairness perception. The structural equation modeling analysis results show that information sharing has a positive but not a significant effect on distributive fairness (Table 3 ). In addition, information sharing shows a relatively high positive and significant effect on procedural fairness $(\beta=0.56, p<$ 0.001 ). This result rejected Hla but supported H1b. The path from price satisfaction to fairness perceptions indicates that price satisfaction has positive and significant effects on both distributive fairness $(\beta=0.57, p<0.001)$ and procedural fairness $(\beta=0.16, p<0.01)$. Similarly, environmental stability has a positive and significant influence on distributive fairness $(\beta=0.23, p<0.01)$ and procedural fairness $(\beta=0.31$, $p<0.001)$. So far, all the hypotheses concerning antecedents to fairness perception were confirmed, except for Hla.

We found that dependence played a mediating role in the relationship between fairness perceptions and relationship
TABLE 3: Results of hypothesis tests.

\begin{tabular}{lc}
\hline Antecedents $\rightarrow$ dependent variable & $\beta$ \\
\hline H1a: Information sharing $\rightarrow$ distributive fairness & 0.14 \\
H1b: Information sharing $\rightarrow$ procedural fairness & $0.56^{* * *}$ \\
H2a: Price satisfaction $\rightarrow$ distributive fairness & $0.57^{* * *}$ \\
H2b: Price satisfaction $\rightarrow$ procedural fairness & $0.16^{* *}$ \\
H3a: Environmental stability $\rightarrow$ distributive stability & $0.23^{* *}$ \\
H3b: Environmental stability $\rightarrow$ procedural fairness & $0.31^{* * *}$ \\
H4a: Distributive fairness $\rightarrow$ trust & $0.29^{* *}$ \\
H4b; Distributive fairness $\rightarrow$ commitment & $0.21^{*}$ \\
H5a: Procedural fairness $\rightarrow$ trust & $0.61^{* * *}$ \\
H5b: Procedural fairness $\rightarrow$ commitment & $0.66^{* * *}$ \\
H6a: Distributive fairness $\times$ dependence $\rightarrow$ trust & $0.23^{* *}$ \\
H6b: Distributive fairness $\times$ dependence $\rightarrow$ commitment & 0.14 \\
H7a: Procedural fairness $\times$ dependence $\rightarrow$ trust & $0.43^{* * *}$ \\
H7b: Procedural fairness $\times$ dependence $\rightarrow$ commitment & $0.52^{* * *}$ \\
\hline
\end{tabular}

${ }^{*} p<0.05 ;{ }^{* *} p<0.01 ;{ }^{* * *} p<0.001$.

quality. We used a control variable method to analyze the effects of dependence. When dependence was absent, distributive fairness had a positive and significant effect on trust $(\beta=0.29, p<0.01)$ and commitment $(\beta=0.21$, $p<0.05)$. Hypotheses H4a and H4b were thereby supported. Procedural fairness also had a positive and significant effect on trust and commitment, supporting H5a and H5b. However, it is worth noting that the effect of procedural fairness is much stronger than that of distributive fairness (trust: $\beta=0.61, p<0.001$; commitment: $\beta=0.66, p<$ 0.001). Hypotheses H6 and H7 asserted that dependence has a mitigating effect on the link between fairness perception and relationship quality. H6a and H6b were verified by the results, in regard to dependence. The positive effect in the path from distributive fairness $\times$ dependence to trust $(\beta=$ $0.23, p<0.01)$ and commitment $(\beta=0.14)$ was less than the condition without dependence. By comparing the path from procedural fairness $x$ dependence to trust $(\beta=0.43$, $p<0.001)$ and commitment $(\beta=0.52, p<0.001)$ with the 
path from procedural fairness to trust and commitment, hypotheses $\mathrm{H} 7 \mathrm{a}$ and $\mathrm{H} 7 \mathrm{~b}$ were also confirmed. In summary, except for Hla, all the hypotheses we proposed are approved. Moreover, we computed the indirect effect of each antecedent dimension on relationship quality with fairness perceptions as a mediating variable. Following Bollen's [71] approach, the indirect effects of the mutual antecedents of information sharing, price satisfaction, and environmental stability on trust are $0.38,0.26$, and 0.26 , respectively, and the effects on commitment are $0.40,0.23$, and 0.25 , respectively. In general, information sharing imposes the strongest effects on relationship quality via fairness perceptions.

\section{Discussion and Implications}

The objective of this study is to explore the effects of antecedents (information sharing, price satisfaction, and environmental stability) on fairness perceptions (distributive fairness and procedural fairness) perceived by the agricultural product suppliers. In addition, this study examines the effects of fairness perceptions on relationship quality (i.e., trust and commitment) and also undertakes research regarding the moderating effects of dependence in regard to the impact path from fairness perceptions to relationship quality.

Through a structural equation modeling analysis of 450 agricultural product suppliers in China, we found that the antecedents have a positive effect on suppliers' fairness perceptions. In addition to this, the results revealed the sensitivity of different aspects of fairness perceptions to various antecedents.

These results enrich our existing understanding of fairness theory [61]. Many previous studies only focus on the ways in which fairness perceptions affect relationship quality or supply chain partnerships, while the effects of antecedents, such as information sharing, price satisfaction, and environmental stability, on fairness perception are also important. Particularly, the antecedents profoundly influence supply chain relationship quality via fairness perceptions as well. Our results report that, within our sample collected from the agricultural product industry in China, the antecedents of fairness perceptions could enhance suppliers' fairness perceptions. Specifically, information sharing and environmental stability have strong positive effects on procedural fairness. Distributive fairness was found to be more sensitive to price satisfaction. These findings suggest that, in highly asymmetrical relationships, such as between a powerful retailer or distributor and a vulnerable agricultural product supplier, the antecedents of fairness perceptions will determine fairness perceptions with pertinence. Therefore, some specific interpretations were necessary for us to explain our results.

In addition, we found that information sharing has a strong effect $(\beta=0.56, p<0.001)$ on procedural fairness. This finding is consistent with existing information regarding the agricultural industry in China. Chinese suppliers rarely have the opportunities to reach consumers and most of their production actions are based on the family unit. The farmers scale is so small that they lack advanced management concepts and enough technical supports to predict future demands and production situations accurately. Therefore, agricultural product suppliers, composed of working class households, seldom make explicit output plans or deliberately select the varieties of agricultural products to produce in the future. This condition was also one of the prime reasons leading to falls in sales stock-out of products. In contrast to suppliers, retailers can easily obtain consumption information regarding consumers; and consequently, they have more accurate ideas about consumer demands. For instance, some supermarkets, such as Carrefour and Walmart, have conducted consumer consumption data analyses to make reasonable plans for commodity procurement. However, suppliers lack effective approaches to gaining valuable consumers feedback, and they have to place their hopes in retailers or distributors to acquire market information. If retailers share consumers' feedback and market information with suppliers, the information received from retailers will help suppliers make production plans and thereby avoid unnecessary losses caused by excessive production. Thus, suppliers are eager for an equal market. When retailers attach importance to information sharing, the suppliers will perceive fairness as being present.

Our results also suggest that price satisfaction has a more positive effect on distributive fairness $(\beta=0.57, p<0.001)$ than procedural fairness $(\beta=0.16, p<0.01)$. The reasonable interpretation for the significant positive effect of procedural fairness is that suppliers have to sell their products as quickly as possible due to the perishability of agricultural products, which eventually weakens their initiative in the price setting process. The procurement prices offered by retailers are the key factor for distributing the common incomes of the agricultural supply chains and are also connected to suppliers' profits. In other words, procurement prices determine the fairness of income distribution. Thus, suppliers perceive high levels of distributive fairness if they sell their products at satisfying prices.

In order to scrutinize the effect of market environment on fairness perceptions, we conducted several investigations on environmental stability, which involved demand scales and marketing situations. Our results provided full support for our propositions regarding the positive effects of environmental stability on the fairness perceptions. These results indicate that if future market demand scales and sale volumes are predicted accurately, the level of distributive fairness $(\beta=0.23, p<0.01)$ and procedural fairness $(\beta$ $=0.31, p<0.001)$ will increase. This finding is different from those in regard to other industries, such as climate and geographical location, because agricultural outputs possess characteristics of uncertainty. It is necessary for suppliers to maintain environmental stability. We also found that environmental stability has a strong effect on procedural fairness, because long production cycles make it difficult for suppliers to accurately predict the market situation of agricultural products. Therefore, they need outside supports, such as production technology, equipment, and market information, to regulate production. The supports will help suppliers avoid losses from low yields or overproduction, thereby increasing the suppliers' sense of procedural fairness in the supply 
chain mechanism. Therefore, we conclude that, compared to distributive fairness, environmental stability plays a crucial role in the suppliers' perceptions of procedural fairness.

In addition to this, the results of the investigation revealed that procedural fairness has a strong positive effect on trust ( $\beta$ $=0.61, p<0.001)$ and commitment $(\beta=0.66, p<0.001)$. It is worth noting that this result is opposite to prior studies, which report that procedural fairness has no significant impact on trust and commitment, based on research about the automobile manufacturing industry [23]. This result demonstrates that, in agricultural product supply chains, procedural fairness is the prime factor for improving relationship quality. Because vulnerable suppliers are sensitive to procedural fairness, retailers need to proactively formulate a fair cooperation procedure in order to maintain a high level of relationship quality with suppliers. We used two interaction paths (distributive fairness $x$ dependence and procedural fairness $x$ dependence) to perform a moderation test and explored the impact of dependence on the positive effect of fairness perceptions on relationship quality. Under the condition of considering the relational dependence perspectives of suppliers, the positive effect of fairness perceptions on relationship quality is decreased. Dependence is the main element in an asymmetrical environment, and therefore dependence has a negative influence on relationship quality [72]. In an asymmetrical environment, such as in agricultural supply chains, suppliers lack long-lasting selling lines because the number of suppliers is far greater than that of retailers. As a consequence of these issues, suppliers have to rely on retailers or distributors in many ways to ensure their profits. If suppliers' dependence increases, greater losses will be incurred if retailers breach cooperation contracts. This perspective also damages the relationship quality between supply chain members. Hence, an effective way to improve relationship quality is one of the most important policies for governmental regulators to formulate for suppliers, which would contribute to creating an equal supply chain mechanism and, in turn, improve the partnership between suppliers and retailers.

We also scrutinized the indirect effects of antecedents on relationship quality. We found that indirect positive effects of information sharing, price satisfaction, and environmental stability on trust are $0.38,0.26$, and 0.26 , respectively, and the indirect positive effects of these antecedents on commitment are $0.40,0.23$, and 0.25 , respectively. We found that the positive effects of antecedents on fairness perceptions could enhance supply chain relationship quality. The result also suggested that information sharing had the strongest indirect positive effect on trust and commitment, because information sharing of the retailer with suppliers will increase the trust of suppliers in retailers. It would have been concluded that information sharing plays a key role for supply chains to increase their relationship quality from an indirect pattern.

5.1. Theoretical Implications. Several theoretical implications can be deduced from our study. First, we add antecedents to organizational fairness research in supply chain management. Prior studies have traditionally focused on the effect of fairness perceptions on relationship quality or supply chain performance and have failed to take into account the impact of the antecedents of fairness perceptions on relationship quality. This study fills this gap by conducting antecedents of fairness perception model in interorganizational circumstances and exploring the ways in which the antecedents change fairness perceptions and relationship quality of agricultural product supply chains. We found that information sharing, price satisfaction, and environmental stability had significant positive effects on suppliers' fairness perceptions. By comparing the strength of the indirect effects of different dimensions of antecedents on fairness perceptions, some factors including information sharing and price satisfaction had a greater effect on procedural fairness and distributive fairness, respectively, than others. Our results also revealed that antecedents had positive indirect effects on trust and commitment, and the effects of information sharing are the strongest. Thus, our findings indicate that suppliers were majorly concerned about the predictability of future market trends and market information provided by retailers, from the perspective of procedural fairness. Furthermore, rational and considerable procurement prices inspire the distributive fairness of suppliers. These two dimensions of fairness perceptions reduce the conflict and uncertainty in the supply chain operating process, leading to improving the supply chain members' satisfaction and maintaining efficient functioning in the long run.

To further investigate fairness perceptions in partnerships, we assessed the effect of fairness perceptions on relationship quality of agricultural product supply chains. The results demonstrated that suppliers' procedural fairness perceptions had stronger impacts on trust and commitment than suppliers' distributive fairness. This result is largely in line with Kumar et al. [2]. In order to draw on the results regarding the way in which information sharing and environmental stability have a more significant impact on procedural fairness than distributive fairness, we verified the mediating function of the fairness perceptions in the path of antecedents to relationship quality, revealing that highly favorable information sharing exerts the strongest positive effect on trust and commitment. Therefore, we support the argument that antecedents play an important role in indirectly improving relationship quality.

Moreover, we introduced dependence into the link between fairness perception and relationship quality to test its moderating influence with the help of an interaction approach. The results of our analysis demonstrate that suppliers' dependence mitigates the effect of distributive fairness and procedural fairness on both dimensions of relationship quality. This finding suggests that relationship quality is less sensitive to fair treatment from retailers when the dependence of suppliers is taken into consideration. In fact, when a supplier is highly dependent on a dominating retailer, the relationship quality will not improve effectively, even if retailers treat them fairly. Hence, under such circumstances, suppliers may adopt two alternative strategies: the first strategy is that they terminate their cooperation with retailers to avoid the benefit losses caused by high levels of dependence, and the other strategy is that they maintain 
their cooperation with retailers in view of the cost increase, due to the transfer of partners. However, problems regarding profit conflict and unfair treatment also exist in the latter option and so this situation is not helpful in maintaining the safety of food quality. In order to ensure high levels of cooperation quality within a supply chain, third-party regulators should formulate relevant policies to reduce the dependence of suppliers on retailers, thereby balancing both parties' positions in the supply chain.

5.2. Managerial Implications. Our findings have practical implications for both managers of supply chain members and governmental regulators. Above all, improving the management quality of agricultural products requires managers to understand what is harmful to the quality of agricultural products and the interactional relationship between internal systematic factors. Researchers have recognized that longterm stable relationships within supply chains have positive effects on the performance of the supply chains and the quality of the products [73]. Therefore, improving supply chain members' relationship quality is crucial in promoting the quality of products.

First, both supply chain members and governmental regulators should understand that information sharing is the main driver of procedural fairness, trust, and commitment. Our study reveals that information sharing has the strongest direct effect on procedural fairness and the strongest indirect effect on trust and commitment. In reality, agricultural production in China still operates largely within a small economy and lacks aspects of large-scale operations. There are a number of information blind spots in agricultural product supply chains. As a result of this, there exists serious information asymmetry between suppliers and retailers. Indeed, in our reviews, some interviewees claimed that they usually choose agricultural products to plant depending on the prices of the last year. This kind of behavior easily incurs an imbalance between supplies and demands. Our finding verifies the important impact of information sharing on relationship quality and provides clear evidence to prove that high levels of information fairness are necessary for a healthy relationship. Thus, governmental regulators should provide some ways of sharing market information, such as building an Internet platform which allows retailers to update the demand situation of products, or suppliers issuing information about inventories and products for sale.

Second, retailers should pay more attention to suppliers' fairness and preserve suppliers' fairness in all aspects. Although antecedents (such as information sharing) are important in increasing relationship quality, they are not direct drivers. Rather, our results show that relationship quality has a closer connection to distributive fairness and process fairness. Retailers should set reasonable prices to ensure the fair allocation of supply chain profits and the legitimate earning of suppliers in order to ensure that suppliers' distributive fairness can be established. One important finding of our study is that procedural fairness has a stronger effect on relationship quality than distributive fairness. Hence, the recommendation for retailers is that they should preferentially focus on the fairness during transaction processes, such as responding to the requests of suppliers in a timely manner and being proactive in communicating with suppliers. Furthermore, during our interviews, we investigated the effects of retailers' attitudes on suppliers' fairness perceptions and found that bad manners could also damage procedural fairness. Our survey results reveal that $38 \%$ of suppliers decided to terminate their cooperation with current retailers due to the offensive behaviors of that retailer, such as a rude or discourteous attitude. Therefore, retailers should realize that vulnerable suppliers are unlikely to tolerate impolite behaviors. To consolidate the fairness perceptions of suppliers, retailers should train their employees to communicate and interact with suppliers in an appropriate manner. Although the four dimensions of fairness are all important in the supply chain, the agricultural product supply chain we focused on is a loose supply chain. The cooperation between the supplier and the retailer is a loose interorganization cooperation. Therefore, distributive fairness and process fairness play a much more important role in relationship than informational fairness and interpersonal fairness. There also exists a close supply chain in which the cooperation relationship between the supplier and the retailer is a close cooperation. For example, the supply chain of Yonghui supermarket and its supplier of proprietaries is a close supply chain. Informational fairness and interpersonal fairness probably play a much more important role in relationship quality in such supply chain.

Third, governmental regulators should support and help small suppliers through various ways. The results of our study demonstrate that dependence mitigates the positive effects of fairness perceptions on relationship quality. Indeed, suppliers are more likely to suffer unfair treatment, such as a breach of contracts or the forcing down of procurement prices, if they are extremely dependent on retailers. For instance, one of our interviewees mentioned how his distributors had violated their contract: "The distributor issued an order request about purchasing all the products after harvest, but during the production they had not provided any supports or informed us the specification of the goods. Finally, after we had grown the products, they said our products were unqualified and refused to purchase any of them." Thus, governmental regulators need to supervise the transaction behavior in agricultural product supply chains. For example, regulators could enforce various measures or establish credibility and benefit sharing incentive mechanisms to closely link the benefits of the two parties, thereby avoiding situations in which retailers harm the interests of suppliers. Moreover, dispersing small-scale farming is the main reason why suppliers assume an inferior position in the supply chain. Hence, integrating multisuppliers and expanding the scale of production appropriately would help suppliers protect their lawful rights and realize the objectives of food quality management [74].

5.3. Limitations and Future Research. Despite the great theoretical and managerial contributions of this study, there are still few limitations. First, a primary finding of this study concerns the moderating effects of dependence on the path from fairness perceptions to relationship quality. However, there is the possibility that antecedents to fairness perceptions also 
have impacts on dependence. Therefore, future research may consider dependence as a dependent variable and analyze the interactions between dependence and the antecedents to fairness perceptions. The second limitation is that we only focus on the supplier side of the supply chain relationship. Retailers' perceptions are also essential for promoting the relationship quality of supply chains. Therefore, further studies are needed to examine the relationships between every construct from retailers' perspectives. Third, our data were collected from a single country (China). Although it is helpful to eliminate transnational variations as latent noises in the model, this may lead to our conclusions suffering from a lack of universality. Future studies could collect data from multiple countries to testify how different geographical environments influence the supplier-retailer relationship in supply chains.

\section{Conflicts of Interest}

The authors declare that they have no conflicts of interest.

\section{Acknowledgments}

The authors would like to acknowledge the financial support that they received from the National Natural Science Foundation of China (71301073, 71571102, and 71571099), the Major Program of National Social Science Foundation of China (12\&ZD204), the National Social Science Foundation of China (16FGL011), and the Social Science Innovation Team Foundation of Nanjing Tech University (SKTD2017001).

\section{References}

[1] U. Broll, P. Welzel, and K. P. Wong, "Price risk and risk management in agriculture," Contemporary Economics, vol. 7, no. 2, pp. 17-20, 2013.

[2] N. Kumar, L. K. Scheer, and J. E. Steenkamp, "The effects of supplier fairness on vulnerable resellers," Journal of Marketing Research, vol. 32, no. 1, pp. 54-65, 1995.

[3] M. Rabin, "Incorporating fairness into game theory and economics," American Economic Review, vol. 83, no. 5, pp. 12811302, 1993.

[4] S. A. Samaha, R. W. Palmatier, and R. P. Dant, "Poisoning relationships: Perceived unfairness in channels of distribution," Journal of Marketing, vol. 75, no. 3, pp. 99-117, 2011.

[5] F. Qin, F. Mai, M. J. Fry, and A. S. Raturi, "Supply-chain performance anomalies: Fairness concerns under private cost information," European Journal of Operational Research, vol. 252, no. 1, pp. 170-182, 2016.

[6] X. Zhao, B. Huo, W. Selen, and J. H. Y. Yeung, "The impact of internal integration and relationship commitment on external integration," Journal of Operations Management, vol. 29, no. 1-2, pp. 17-32, 2011.

[7] Y. Luo, "How important are shared perceptions of procedural justice in cooperative alliances?" Academy of Management Journal (AMJ), vol. 48, no. 4, pp. 695-709, 2005.

[8] C. Yilmaz, B. Sezen, and E. Tumer Kabadayi, "Supplier fairness as a mediating factor in the supplier performance-reseller satisfaction relationship," Journal of Business Research, vol. 57, no. 8, pp. 854-863, 2004.
[9] J. R. Brown, A. T. Cobb, and R. F. Lusch, "The roles played by interorganizational contracts and justice in marketing channel relationships," Journal of Business Research, vol. 59, no. 2, pp. 166-175, 2006.

[10] D. A. Griffith, M. G. Harvey, and R. F. Lusch, "Social exchange in supply chain relationships: The resulting benefits of procedural and distributive justice," Journal of Operations Management, vol. 24, no. 2, pp. 85-98, 2006.

[11] J. M. George and G. R. Jones, "The role of time in theory and theory building," Journal of Management, vol. 26, no. 4, pp. 657$684,2000$.

[12] J. S. Adams, "Inequity in social exchange," in Advances in Experimental Social Psychology, pp. 267-299, Academic Press, New York, NY, USA, 1965.

[13] S. Suh, "Fairness and relationship quality perceived by local suppliers: In search of critical success factors for international retailers," Journal of Global Marketing, vol. 18, no. 1-2, pp. 5-19, 2004.

[14] Y. Liu, Y. Huang, Y. Luo, and Y. Zhao, "How does justice matter in achieving buyer-supplier relationship performance?" Journal of Operations Management, vol. 30, no. 5, pp. 355-367, 2012.

[15] R. J. Bies and J. S. Moag, "Interactional justice: Communication criteria of fairness," in Research on negotiation in organizations, R. J. Lewicki, B. H. Sheppard, and M. H. Bazerman, Eds., vol. 1, pp. 43-55, JAI Press, Greenwich, CT, USA, 1986.

[16] J. Greenberg, "Employee theft as a reaction to underpayment inequity: the hidden cost of pay cuts," Journal of Applied Psychology, vol. 75, no. 5, pp. 561-568, 1990.

[17] J. Greenbreg, "The social side of fairness: interpersonal and informational classes of organizational justice," in Justice in the workplace: Approaching fairness in human resource management, R. Cropanzano, Ed., Erlbaum, Hilladale, NJ, USA, 1993.

[18] Y. Luo, "The independent and interactive roles of procedural, distributive, and interactional justice in strategic alliances," Academy of Management Journal (AMJ), vol. 50, no. 3, pp. 644664, 2007.

[19] J. Thibaut and L. Walker, Procedural justice: A psychological analysis, Lawrence Erlbaum Associates, Hillsdale, NJ, USA, 1975.

[20] J. A. Colquitt, M. J. Wesson, C. O. L. H. Porter, D. E. Conlon, and K. Y. Ng, "Justice at the millennium: A meta-analytic review of 25 years of organizational justice research," Journal of Applied Psychology, vol. 86, no. 3, pp. 425-445, 2001.

[21] Y. Luo, "Procedural fairness and interfirm cooperation in strategic alliances," Strategic Management Journal, vol. 29, no. 1, pp. 27-46, 2008.

[22] D. P. S. Chia, C. M. Lau, and S. L. C. Tan, “The relationships between performance measures and employee outcomes: The mediating roles of procedural fairness and trust," Studies in Managerial and Financial Accounting, vol. 28, pp. 203-232, 2014.

[23] G. Zaefarian, Z. Najafi-Tavani, S. C. Henneberg, and P. Naudé, "Do supplier perceptions of buyer fairness lead to supplier sales growth?" Industrial Marketing Management, vol. 53, pp. 160-171, 2015.

[24] J. K. Huntley, "Conceptualization and measurement of relationship quality: Linking relationship quality to actual sales and recommendation intention," Industrial Marketing Management, vol. 35, no. 6, pp. 703-714, 2006.

[25] L. A. Crosby, K. R. Evans, and D. Cowles, "Relationship quality in services selling: an interpersonal influence perspective," Journal of Marketing, vol. 54, no. 3, pp. 68-81, 1990. 
[26] W. Lu and J. Wang, “The influence of conflict management styles on relationship quality: The moderating effect of the level of task conflict," International Journal of Project Management, vol. 35, no. 8, pp. 1483-1494, 2017.

[27] M. Holmlund, "The D and D model - Dimensions and domains of relationship quality perceptions," The Service Industries Journal, vol. 21, no. 3, pp. 13-36, 2001.

[28] J. Mohr and R. Spekman, "Characteristics of partnership success: Partnership attributes, communication behavior, and conflict resolution techniques," Strategic Management Journal, vol. 15, no. 2, pp. 135-152, 1994.

[29] K. Storbacka, T. Strandvik, and C. Gronroos, "Managing Customer Relationships for Profit: The Dynamics of Relationship Quality," International Journal of Service Industry Management, vol. 5, no. 5, pp. 21-38, 1994.

[30] J. A. Young, Strategic Alliances: Are They Relational by Definition, Indiana State University, Indiana, Ind, USA, 2000.

[31] V. Kashyap and E. Sivadas, "An exploratory examination of shared values in channel relationships," Journal of Business Research, vol. 65, no. 5, pp. 586-593, 2012.

[32] A. G. Abdul-Muhmin, "Instrumental and interpersonal determinants of relationship satisfaction and commitment in industrial markets," Journal of Business Research, vol. 58, no. 5, pp. 619-628, 2005.

[33] J. C. Anderson and J. A. Narus, "A model of distributor firm and manufacturer firm working partnerships," Journal of Marketing, vol. 54, no. 1, pp. 42-58, 1990.

[34] I. Geyskens, J.-B. E. M. Steenkamp, and N. Kumar, "Generalizations about trust in marketing channel relationships using meta-analysis," International Journal of Research in Marketing, vol. 15, no. 3, pp. 223-248, 1998.

[35] K. D. Ruyter, L. Moorman, and J. Lemmink, "Antecedents of Commitment and Trust in Customer-Supplier Relationships in High Technology Markets," Industrial Marketing Management, vol. 30, no. 3, pp. 271-286, 2001.

[36] L. G. Zucker, "Production of trust: Institutional sources of economic structure," in Research in Organizational Behavior, vol. 8, pp. 53-111, 1986.

[37] S. Ganesan, "Determinants of Long-Term Orientation in BuyerSeller Relationships," Journal of Marketing, vol. 58, no. 2, p. 1, 1994.

[38] S. Ganesan, S. R. Brown, B. J. Mariadoss, and H. Ho, "Buffering and amplifying effects of relationship commitment in businesstobusiness relationships," Journal of Marketing Research, vol. 47, no. 2, pp. 361-373, 2010.

[39] J. L. Skeem, J. E. Louden, D. Polaschek, and J. Camp, "Assessing relationship quality in mandated community treatment: blending care with control," Psychological Assessment, vol. 19, no. 4, pp. 397-410, 2007.

[40] A. Gustafsson, M. D. Johnson, and I. Roos, "The effects of customer satisfaction, relationship commitment dimensions, and triggers on customer retention," Journal of Marketing, vol. 69, no. 4, pp. 210-218, 2005.

[41] E. Anderson and B. Weitz, "Determinants of Continuity in Conventional Industrial Channel Dyads," Marketing Science, vol. 8, no. 4, pp. 310-323, 1989.

[42] S. B. Modi and V. A. Mabert, "Supplier development: Improving supplier performance through knowledge transfer," Journal of Operations Management, vol. 25, no. 1, pp. 42-64, 2007.

[43] J. Li, R. Sikora, M. J. Shaw, and G. Woo Tan, "A strategic analysis of inter organizational information sharing," Decision Support Systems, vol. 42, no. 1, pp. 251-266, 2006.
[44] F. Ye and X. J. Xu, "Impact of trust and relationship commitment among supply chain partners on information sharing and operational performance," Systems Engineering: Theory Practice, vol. 29, no. 8, pp. 36-48, 2009.

[45] R. B. Handfield and C. Bechtel, "The role of trust and relationship structure in improving supply chain responsiveness," Industrial Marketing Management, vol. 31, no. 4, pp. 367-382, 2002.

[46] P. Y. Tong and J. L. Crosno, "Are information asymmetry and sharing good, bad, or context dependent? A meta-analytic review," Industrial Marketing Management, vol. 56, pp. 167-180, 2016.

[47] G. L. Frazier, "Organizing and managing channels of distribution," Journal of the Academy of Marketing Science, vol. 27, no. 2, pp. 226-240, 1999.

[48] A. Hellberg-Bahr and A. Spiller, "How to treat farmers fairly? Results of a farmer survey?" International Food and Agribusiness Management Review, vol. 15, no. 3, pp. 87-98, 2012.

[49] T. C. Schroeder, C. E. Ward, J. R. Mintert, and D. S. Peel, "Value-Based Pricing of Fed Cattle: Challenges and Research Agenda," Review of Agricultural Economics, vol. 20, no. 1, p. 125, 1998.

[50] R. M. Morgan and S. D. Hunt, "The Commitment-Trust Theory of Relationship Marketing," Journal of Marketing, vol. 58, no. 3, p. 20, 1994.

[51] J. B. Heide, "Interorganizational Governance in Marketing Channels," Journal of Marketing, vol. 58, no. 1, p. 71, 1994.

[52] S. Aryee, P. S. Budhwar, and Z. X. Chen, “Trust as a mediator of the relationship between organizational justice and work outcomes: Test of a social exchange model," Journal of Organizational Behavior, vol. 23, no. 3, pp. 267-285, 2002.

[53] K. M. Ellis, T. H. Reus, and B. T. Lamont, "The effects of procedural and informational justice in the integration of related acquisitions," Strategic Management Journal, vol. 30, no. 2, pp. 137-161, 2009.

[54] J. A. Colquitt and J. B. Rodell, "Justice, trust, and trustworthiness: A longitudinal analysis integrating three theoretical perspectives," Academy of Management Journal (AMJ), vol. 54, no. 6, pp. 1183-1206, 2011.

[55] M. Hemmert, D. Kim, J. Kim, and B. Cho, "Building the supplier's trust: Role of institutional forces and buyer firm practices," International Journal of Production Economics, vol. 180, pp. 25-37, 2016.

[56] T. R. Tyler and E. A. Lind, "A Relational Model of Authority in Groups," Advances in Experimental Social Psychology, vol. 25, no. C, pp. 115-191, 1992.

[57] M. Zhang and B. Huo, "The impact of dependence and trust on supply chain integration," International Journal of Physical Distribution and Logistics Management, vol. 43, no. 7, pp. 544563, 2013.

[58] J. B. Heide and G. John, “The role of dependence balancing in safeguarding transaction-specific assets in conventional channels," Journal of Marketing, vol. 52, no. 1, p. 20, 1988.

[59] I. Geyskens, J.-B. E. M. Steenkamp, L. K. Scheer, and N. Kumar, "The effects of trust and interdependence on relationship commitment: A trans-Atlantic study," International Journal of Research in Marketing, vol. 13, no. 4, pp. 303-317, 1996.

[60] B. Lauranne, "Vertical trade relationships: The role of dependence and symmetry in attaining organizational goals," Journal of Marketing Research, vol. 29, no. 1, pp. 65-75, 1992. 
[61] D. A. Griffith, J. J. Hoppner, H. S. Lee, and T. Schoenherr, "The Influence of the Structure of Interdependence on the Response to Inequity in Buyer-Supplier Relationships," Journal of Marketing Research, vol. 54, no. 1, pp. 124-137, 2017.

[62] G. L. Frazier, E. Maltz, K. D. Antia, and A. Rindfleisch, "Distributor sharing of strategie information with suppliers," Journal of Marketing, vol. 73, no. 4, pp. 31-43, 2009.

[63] J. L. Price and C. W. Mueller, Handbook of Organizational Measurements, Pittman, Marshfield, Mass, USA, 1986.

[64] W. C. Kim and R. A. Mauborgne, "Implementing global strategies: The role of procedural justice," Strategic Management Journal, vol. 12, no. 1 S, pp. 125-143, 1991.

[65] M. A. Konovsky and R. Cropanzano, "Perceived Fairness of Employee Drug Testing as a Predictor of Employee Attitudes and Job Performance," Journal of Applied Psychology, vol. 76, no. 5, pp. 698-707, 1991.

[66] J. P. Meyer, N. J. Allen, and C. A. Smith, "Commitment to organizations and occupations: extension and test of a threecomponent conceptualization," Journal of Applied Psychology, vol. 78, no. 4, pp. 538-551, 1993.

[67] J. F. Hair, W. C. Black, B. J. Babin, R. E. Anderson, and R. L. Tatham, Multivariate Data Analysis: A Global Perspective, Prentice Hall, Upper Saddle River, NJ, USA, 2010.

[68] F. Chan, G. K. Lee, E.-J. Lee, C. Kubota, and C. A. Allen, "Structural equation modeling in rehabilitation counseling research," Rehabilitation Counseling Bulletin, vol. 51, no. 1, pp. 44-57, 2007.

[69] B. G. Tabachnick and L. S. Fidell, Using Multivariate Statistics, Allyn and Bacon, Boston, MA, USA, 2007.

[70] C. Fornell and D. F. Larcker, "Evaluating structural equation models with unobservable variables and measurement error," Journal of Marketing Research, vol. 18, no. 1, pp. 39-50, 1981.

[71] K. A. Bollen, Structural Equations with Latent Variables, John Wiley \& Sons, New Jersey, NJ, USA, 1989.

[72] N. Kumar, L. K. Scheer, and J. E. Steenkamp, "The Effects of Perceived Interdependence on Dealer Attitudes," Journal of Marketing Research, vol. 32, no. 3, p. 348, 1995.

[73] B. Fynes, S. de Búrca, and D. Marshall, "Environmental uncertainty, supply chain relationship quality and performance," Journal of Purchasing and Supply Management, vol. 10, no. 4-5, pp. 179-190, 2004.

[74] C. Ménard and P. G. Klein, "Organizational issues in the agrifood sector: Toward a comparative approach," American Journal of Agricultural Economics, vol. 86, no. 3, pp. 750-755, 2004. 


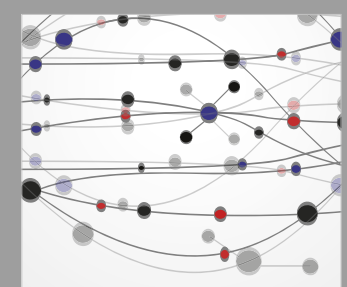

The Scientific World Journal
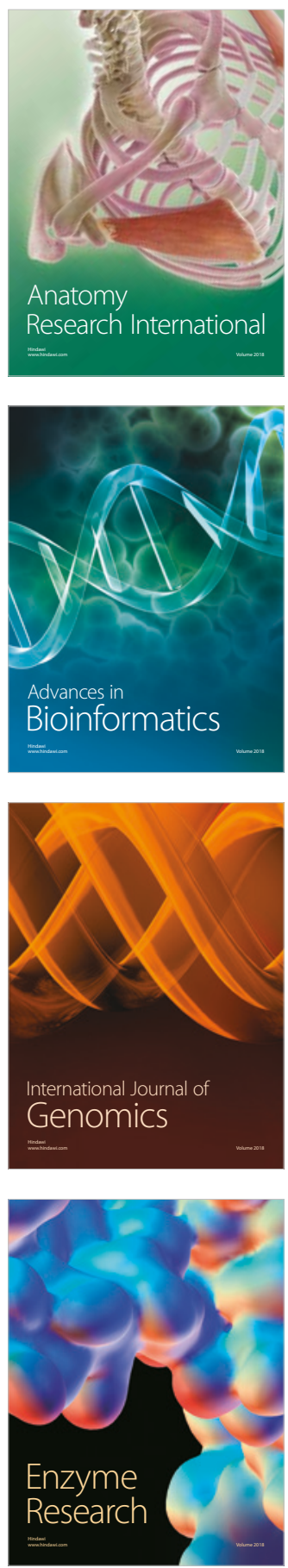
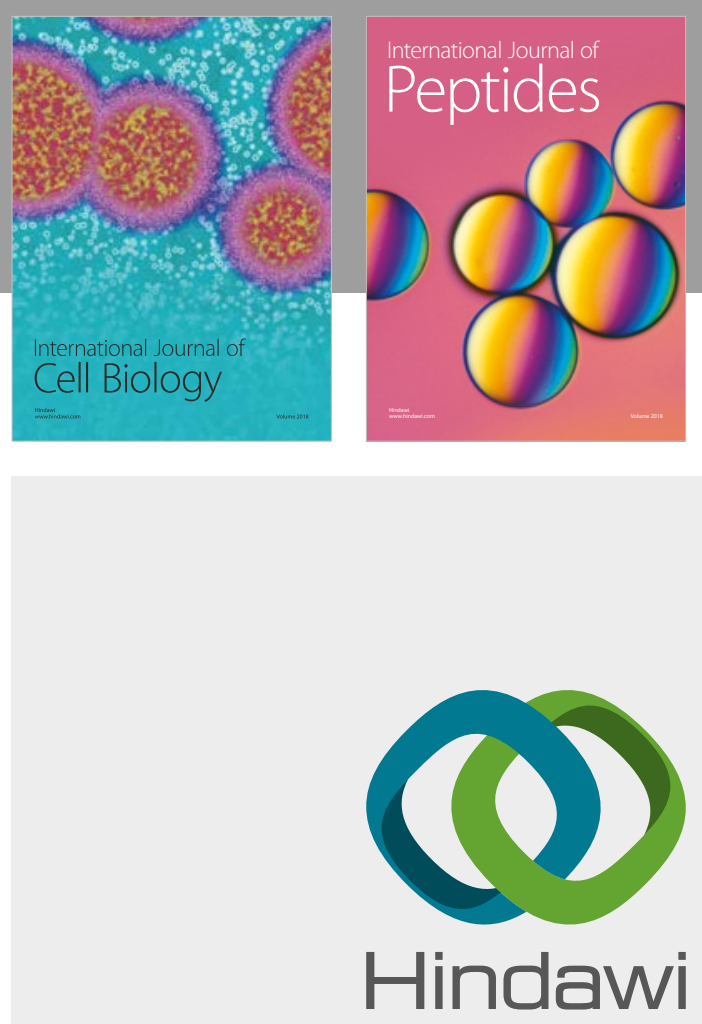

Submit your manuscripts at

www.hindawi.com
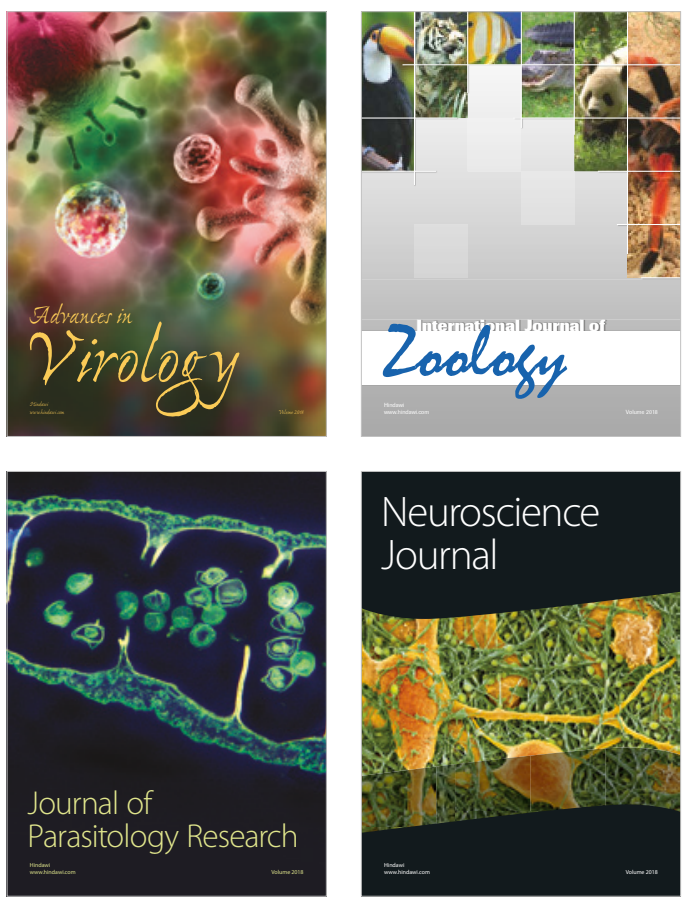
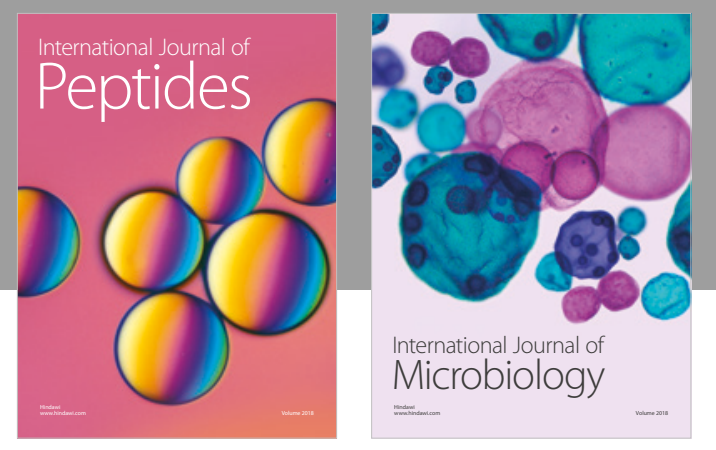

nternational Journal of Microbiology
Journal of
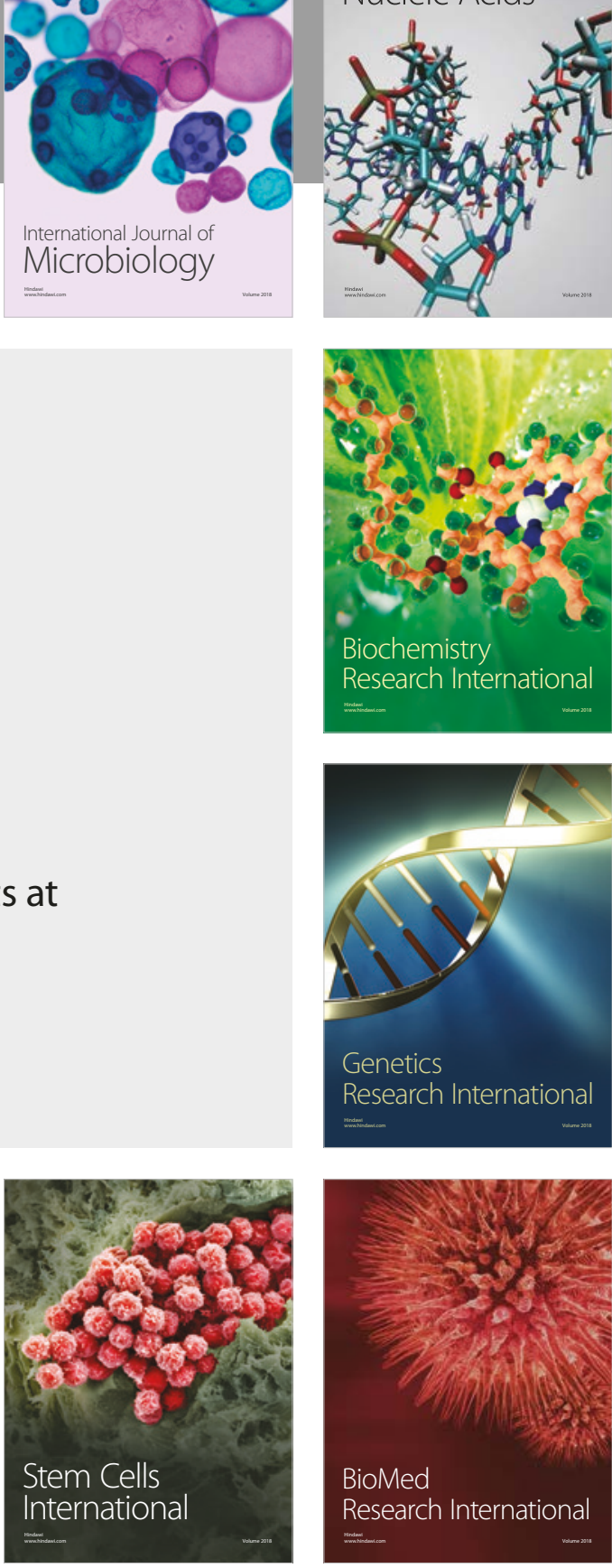
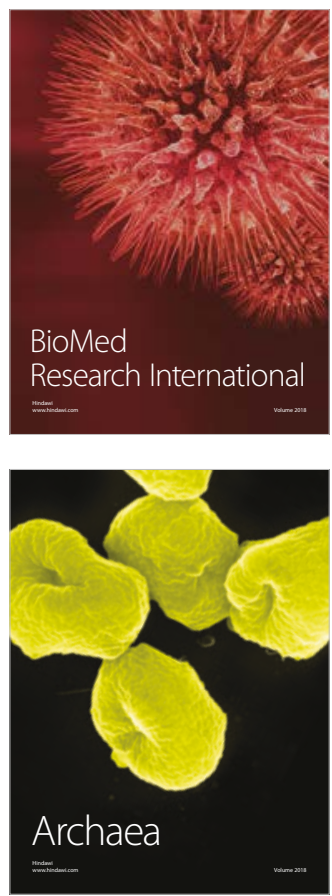